\title{
1861: la emergencia de la educación laica en México*
}

\section{Roberto GoNZÁLEZ ViLLARREAL}

\begin{abstract}
Profesor de la Universidad Pedagógica Nacional (México). Correo electrónico: milak1955@hotmail.com. El autor es doctor en Economía de la Universidad Nacional Autónoma de México (México) y miembro del Sistema Nacional de Investigadores, de la Red Mexicana de Estudios de Movimientos Sociales. Entre sus publicaciones recientes tenemos: "De la Ayotzinapa: la rabia y la esperanza" México: Terracota, (2015) y "secularización a la laicidad educativa en México" en Historia de la Educación (Anuario SAHE), Vol. 15, No. 2 (2014). Entre sus temas de interés están educación laica, movimientos sociales en el capitalismo cognitivo y violencia escolar.
\end{abstract}

\section{Adelina Arredondo}

Investigadora del Instituto de Ciencias de la Educación de la Universidad Autónoma del Estado de Morelos (México). Correo electrónico: adelinaarredondo@yahoo.com. La autora es doctora en Ciencias Sociales de El Colegio de Michoacán A.C (México). Entre sus publicaciones recientes tenemos: "John Dewey en México: una experiencia compartida en el mundo rural" en Espacio, tiempo y educación, Vol. 3 (2016) y "Educación pública y formación de élites: las cátedras y el Instituto Literario de Chihuahua" en Instituciones modernas de educación superior. Institutos científicos y literarios de México siglos XIX y XX, (coord.) Rosalinda Ríos Zúñiga. México: ISUE-Bonilla Artigas (2015). Entre sus temas de interés están historia de la educación, políticas educativas, formación de docentes, género y, sociedad y educación.

Recibido: 26 de agosto de 2015

Aprobado: 10 de junio de 2016

Modificado: 23 de junio de 2016

Artículo de investigación científica

DOI: http://dx.doi.org/10.15648/hc.30.2016.2

* $\quad$ Este artículo forma parte del proyecto: “La educación laica en México: conceptos, políticas y coyunturas" financiado por el Consejo Nacional de Ciencia y Tecnología (México).

Esta publicación está bajo una licencia Creative Commons Reconocimiento-NoComercial 4.0 


\title{
1861: la emergencia de la educación laica en México
}

\section{Resumen}

La educación laica tiene más de siglo y medio de formalizada en la legislación mexicana. En este artículo se exponen las condiciones de emergencia de una educación libre y laica, a partir de la definición de un operador analítico denominado régimen de laicidad. Exponemos el entramado institucional, es decir, jurídico-administrativo, que se construyó entre 1857 y 1863, para identificar las rupturas que se dan en la legislación sobre los contenidos de la instrucción primaria, los problemas de la jurisdicción derivados de un régimen federal en el que son las entidades de la república las que tienen atribución para legislar sobre instrucción, y los problemas conceptuales y administrativos sobre la instrucción pública. El nudo histórico-conceptual de emergencia de la educación laica está conformado por los ensambles que se dan entre los modos de problematizar, conceptualizar y regular la instrucción pública en una república federal después de la Guerra de Reforma. Los conceptos teóricos se despliegan en la exposición histórica, que se fundamente en fuentes primarias de carácter legislativo y administrativo y en fuentes secundarias que permiten reconocer y explicar el problema en un contexto geográfico amplio.

Palabras clave: educación laica, régimen de laicidad, secularización, sistema educativo.

\section{1: The Emergence of Secular Education in Mexico}

\begin{abstract}
Formal Secular education has more than a century and a half in Mexican legislation. In this article, the conditions of emergence of a free and secular education are set out, starting from the definition of an analytic operator called the regime of secularism.The institutional matrix is exposed, it means, legal-administrative, which was built between 1857 and 1863, in order to identify the ruptures that occur in the legislation about the content of primary education; the problems of the jurisdiction derived of a federal regime in which the entities of the Republic are the ones that have attribution to legislate on instruction as well as the conceptual and administrative problems about public instruction. The historical conceptual knot of secular education emergency is formed by assemblies which occur between modes of problematizing, conceptualizing and regulating public instruction in a federal Republic after the Reform War. Those theoretical conceptsare displayed in the historical exhibition, which is based in primary sources of legislative and administrative matter and in secondary sources that allow recognizing and explaining the problem in a geographical broad context.
\end{abstract}

Key words: secular education, regime of laicism, secularization, educationsystem. 


\section{1: a emergência da educação laica em México}

\section{Resumo}

A educação laica tem mais de século e médio de formalizada na legislação mexicana. Neste artigo se expõem as condições de emergência de uma educação livre e laica, a partir da definição de um operador analítico chamado regime de laicidad. Expomos a Trama institucional, isto é, jurídico-administrativo, que se construiu entre 1857 e 1863, para identificar as rupturas que se dão na legislação sobre os conteúdos da instrução primária, os problemas da jurisdição derivados de um regime federal em o que são as entidades da república as que têm atribuição para legislar sobre instrução, e os problemas conceptuais e administrativos sobre a instrução pública. O nodo histórico-conceptual de emergência da educação laica está conformado por monte-los que se dão entre os modos de problematizar, conceptualizar e regular numa república federal após a Guerra de Reforma. Os conceitos teóricos se desdobram na exposição histórica, que se fundamente em fontes primárias de carácter legislativo e administrativo e em fontes secundárias que permitem reconhecer e explicar o problema num contexto geográfico amplo.

Palavras-chave: educação laica, regime de laicidad, secularização, sistema educativo

\section{1: l'émergence de l'éducation laïque au Mexique}

\section{Résumé}

Il y a plus d'un siècle et demi que l'éducation laïque a été formalisée dans la législation mexicaine. Dans cet article, on expose les conditions d'émergence d'une éducation libre et lä̈que, à partir de la définition d'un opérateur analytique appelé régime de laïcité. On présente le tissu institutionnel juridique-administratif construit entre 1857 et 1863, pour identifier les ruptures dans la législation sur les contenus de l'école primaire, les problèmes de la juridiction dérivés d'un régime fédéral dans lequel les entités de la république sont les seules à avoir l'attribution de légiférer sur l'instruction, ainsi que les problèmes conceptuels et administratifs sur l'instruction publique. Le lien historique-conceptuel d'émergence de l'éducation laïque est constitué par les enchainements qu'il y a entre les formes de problématiser et réguler l'instruction publique dans une république fédérale après la Guerre de Réforme. L'analyse historique accomplie se fonde sur des sources primaires à caractère législatif et administratif et sur des sources secondaires qui permettent de reconnaître et d'expliquer le problème dans un contexte géographique ample.

Mots clés: éducation laïque, régime de laïcité, sécularisation, système éducatif. 


\section{INTRODUCCIÓN}

Para muchos, en los circuitos políticos y académicos, la educación laica en México es una conquista de la Revolución Mexicana, dado que el concepto no existía en los textos constitucionales precedentes. La primera Constitución Federal de los Estados Unidos Mexicanos, de 1824, no contiene más referencias a la educación que el artículo 50 fracción I, en las atribuciones del Congreso General:
"Artículo 50: Las facultades exclusivas del Congreso general son las siguientes:
1. Promover la ilustración: asegurando por un tiempo limitado derechos exclusivos a los autores por sus respectivas obras, es- tableciendo colegios de marina, artillería e ingenieros; erigiendo uno o más establecimientos en que se enseñen las ciencias na- turales exactas, políticas y morales, nobles artes y lenguas; sin perjudicar la libertad que tienen las legislaturas para el arreglo de la educación pública en sus respectivos estados"1.

Cada entidad federativa tenía la facultad de normar lo relativo a la instrucción pública en sus respectivos territorios. Los congresos locales promulgaron leyes para promover y administrar la instrucción, pero limitados por el artículo $3^{\circ}$ de la Constitución federal que decretaba que la "Religión de la nación mexicana es y será perpetuamente la católica, apostólica y romana. La nación la protege por leyes sabias y justas, y prohíbe el ejercicio de cualquier otra"2.

La Constitución de 1857 en su artículo $3^{\circ}$ decretó que "La enseñanza es libre. La ley determinará qué profesiones necesitan título para su ejercicio, y con qué requisitos se deben expedir"’3. Esto generó una confusión, durante

\footnotetext{
1 Senado de la República, "Constitución Federal de los Estados Unidos Mexicanos", Constituciones de México (México: Senado de la República, 1991), 81.

2 Acta Constitutiva de la Federación Mexicana (México: Imprenta del Supremo Gobierno en Palacio, México, 1824), 7.

3 Manuel Dublán y José María Lozano, Legislación mexicana o colección completa de las disposiciones legislativas expendidas desde la Independencia de la República. Tomos I al XIX (México: Imprenta del Comercio, de Dublán y Chávez, a cargo de M. Lara, Hijo, 1877), 384.
} 
mucho tiempo, entre educación libre y educación laica, porque se asumía que la libertad completa se conseguía con la "supresión del monopolio del clero", después de que se iniciara la "supresión de los monopolios educativos", durante el breve gobierno de Valentín Gómez Farías, en 18324 La investigación histórica, sin embargo, ha refutado esta hipótesis, al señalar que la libertad de la enseñanza refiere un largo proceso de emancipación de los gremios, el de San Casiano en particular, que inicia en las Reformas Borbónicas a finales del siglo XVIII en la Nueva España ${ }^{5}$.

En otras interpretaciones, la laicidad se confunde con los procesos de secularización, al señalar la lenta definición de otros fines educativos, como la conformación de ciudadanos libres en una nación independiente, la creación de institutos científicos y literarios, los establecimientos de estudios preparatorios, ideológicos y humanidades, de ciencias físicas y matemáticas, de ciencias médicas, eclesiásticas y jurídicas ${ }^{6}$.

Sin embargo, la secularización y la laicidad no son sinónimos, aunque pueden considerarse conceptos relacionados. Mientras la primera se refiere a un largo proceso de "desencantamiento del mundo" (Weber) o de diferenciación de las instituciones políticas y civiles con respecto a las religiosas; la segunda tiene una definición más acotada, refiere procesos jurídico-administrativos. Así, mientras la secularización se relaciona con la valoración de la experiencia en el mundo, la laicidad es un proceso político e institucional, se propone dirigir las conductas, modelar las costumbres, establecer las reglas de juego. Por eso, de lo que se trata en este texto, es de seguir la emergencia de la laicidad en la instrucción pública mexicana, a partir de un operador analítico: el Régimen de laicidad educativa, definido como el "... ensamble de elementos que definen, delimitan y operan la educación laica, de tal forma que las modificaciones en alguno o varios de los elementos

4 Ernesto Meneses Morales, Tendencias educativas oficiales, 1911-1937 (México: CEE, 1986 ), 737.

5 Dorothy Tanck, La educación ilustrada, 1786-1836 (México: El Colegio de México, 1984), $130-135$.

6 Carlos Herrejón Peredo, "Fundación del Instituto Literario del Estado de México: Testimonios históricos" (Toluca: Universidad Autónoma del Estado de México, 1978); Roberto Heredia, "La educación en Michoacán 1831-1861. Datos y cifras (I)", Relaciones No. 21 (invierno de 1985); Francisco García González, Conciencia e inteligencia en Zacatecas. sociedad, educación, historia (1350-1890) (Zacatecas: El Arco y la Lira, Universidad Autónoma de Zacatecas, 1988). 
del régimen alteran el concepto de laicidad, no de manera teorética, sino jurídica, política y administrativamente"

Desde una perspectiva histórico-institucional, no se trata de trazar los cambios semánticos de una definición, o su aparición en las leyes o reglamentos, sino del ensamblaje progresivo de sus piezas, de su armazón jurídica y administrativa; esto es lo que llamamos un régimen y no solamente un concepto, sino su traducción jurídica-administrativa, es decir, política.

Consideramos cambios en el régimen de laicidad los que agregan, modifican o suprimen alguno o algunos de sus elementos, sin alterar sustantivamente su conformación; pero también pueden ocurrir cambios de régimen, cuando se modifican aspectos jurisdiccionales, los propósitos educativos o los agentes involucrados; también ha habido, y hay en la actualidad, propuestas para eliminar la laicidad, introduciendo educación religiosa en la escuela pública, lo que en estricto sentido sería eliminar el régimen. Así, los cambios son de tres tipos: $\boldsymbol{e n}$ el régimen, $\boldsymbol{d} \boldsymbol{e}$ régimen o $\boldsymbol{d e l}$ régimen. Una historia de la laicidad educativa, en consecuencia, trataría de analizar la emergencia del concepto y la conformación del régimen inicial, y luego las progresivas trasformaciones y enlaces de sus elementos constitutivos.

La herramienta metodológica que hemos construido y proponemos en este artículo ha sido elaborada a partir del análisis de los procesos históricos; está basada en acontecimientos concretos y, sin embargo, consideramos que por su carácter abstracto y su utilidad general, es un instrumento útil para el análisis de la laicidad educativa en distintas entidades políticas, regiones, naciones y coyunturas históricas. Una herramienta así permite identificar y explicar mejor los cambios y permanencias históricas. En ese sentido, nuestro objetivo es no solo difundir en el contexto latinoamericano los regímenes de laicidad en México, sino proponer un modo de entendimiento común, de conceptualización generalizable del fenómeno. Si bien la configuración del Estado laico y la laicidad educativa tienen momentos y características similares en América Latina, existen diferencias

7 Adelina Arredondo y Roberto González Villarreal, "La educación laica en las reformas constitucionales, 1917-1993”, Inventio, Vol. 8, No. 16 (sep. 2012-marzo 2013): 49. 
cualitativas y temporales que no se han explorado en un órgano de difusión científica. Para resolver la cuestión de si podríamos o no hablar de similitudes y diferencias en la construcción de la educación laica en los estados latinoamericanos, y más aún, si podríamos o no hablar de un modelo latinoamericano de laicidad educativa, tendríamos primero que poner a la discusión colectiva las características particulares de los procesos en cada país, buscar denominadores comunes que nos permitan comparar y ponderar y después proceder a la síntesis y aventurarse a proponer planteamientos generales.

En este artículo proponemos trazar la emergencia del primer régimen de laicidad educativa, el que denominaremos liberal; es decir, la conformación formal de un sistema de instrucción ajeno a las doctrinas religiosas, los ámbitos de su ejercicio, las particularidades que toma, las sustituciones y extensiones, sus problemas y dificultades, que iniciaron a fines de la guerra de reforma (1857-1860) y se consolidaron después de la Intervención Francesa y el Imperio (1863-1867), en los inicios de la República Restaurada (1867-1869).

Proponemos una perspectiva histórico-institucional, es decir, la conformación de las reglas de juego en que se realiza la instrucción pública y la particular, construida, en un primer momento, a partir de las leyes, reglamentos, circulares, disposiciones, respuestas, aclaraciones y organismos que constituirán el régimen liberal de laicidad, tanto en las legislaciones del Distrito Federal (en adelante DF) y territorios federales, como de las entidades federativas ${ }^{8}$. La hipótesis que queremos destacar es que el primer régimen de laicidad emerge con el triunfo liberal en la guerra de reforma; se interrumpe durante el segundo imperio y se desarrolla en las leyes federales y estatales inmediatamente posteriores al triunfo de la república y

8 La tarea de reunir información legislativa sobre las entidades federativas, entonces independientes y soberanas, es ya motivo de un trabajo de investigación específico, pues hasta hace poco había predominado una visión histórica centrada en el gobierno nacional, lo que no corresponde al periodo de estudio, donde hubo predominancia de la dispersión de las políticas educativas. Como historiadores de la educación, en tanto comunidad científica, no hemos hecho hasta la fecha un trabajo que de cuenta de esta diversidad, y todo intento de reunir información dispersa en torno a cualquier objeto de estudio es ya un avance en ese sentido. 
su restauración, de 1867 en adelante 9 . La consolidación jurídica, política e institucional del régimen liberal y su inserción en los criterios fundamentales del sistema nacional de instrucción, que inicia en 1874 y culmina en la legislación de 1891 y 1907, la trataremos en otras publicaciones.

\section{LAS LEYES DE REFORMA}

La república federal mexicana se estableció en la primera Constitución de 1824, tres años después de ganada la independencia de España. Después de convulsos años de conflictos políticos y guerras civiles y dos repúblicas centralistas (1834-1846 y 1853-1855) en 1855 se restableció la tercera república federal. Ese mismo año el gobierno federal suprimió los fueros eclesiásticos y militares (Ley Juárez), y decretó la libertad de expresión e imprenta (Ley Lafragua). En 1856 decretó la intervención de los bienes eclesiásticos de Puebla, suprimió la coacción civil para los votos religiosos, suprimió la Compañía de Jesús en México (1856), ordenó la desamortización de las propiedades de corporaciones civiles y eclesiásticas (Ley Lerdo), estableció el Registro Civil (Ley Lafragua, 1857). En 1857 se promulgó una nueva Constitución Política Federal, mencionada arriba, en la cual las leyes liberales enunciadas fueron incorporadas. Dos meses después de promulgada la Constitución se prohibió el cobro de derechos y obvenciones parroquiales y del diezmo a las clases menesterosas (Ley Iglesias, 1857) ${ }^{10}$.

Las disposiciones liberales continuaron en el fragor de la Guerra de Reforma desatada por la inconformidad de la Iglesia Católica y los grupos conservadores. En 1859 se promulgó la Ley de Nacionalización de los bienes del clero regular y secular, la Ley de Matrimonio Civil que incluía prescripciones sobre el divorcio y deslegitimaba cualquier otro tipo de matrimonio, la Ley Orgánica del Registro Civil y la secularización de los cementerios. Se derogaron todas las normativas, jurídicas o consuetudinarias

9 Para una síntesis histórica de la laicidad educativa en México véase Adelina Arredondo y Roberto González Villarreal, "De la secularización a la laicidad educativa en México”, Historia de la Educación. Anuario SAHE Vol. 15, No. 2 (2014): 140-167.

10 Sebastián Segura, J., Código de la Reforma o Colección de Leyes, Decretos y Supremas Órdenes, expedidas desde 1856 hasta 1861, Tomo I (México: Imprenta Literaria, 1861). 
por las cuales los funcionarios públicos asistían a los ritos y cultos públicos de las iglesias, y se definieron los días festivos oficiales, incluyendo algunos propios de las fiestas religiosas, en los siguientes términos:

"El C. Benito Juárez, presidente interino constitucional de los Estados Unidos Mexicanos, a sus habitantes, sabed:

Que en uso de las facultades de que me hallo investido, he tenido a bien decretar lo siguiente:

Artículo $1^{\circ}$. Dejan de ser días festivos para el efecto de que se cierren los tribunales, oficinas y comercio, todos los que no queden comprendidos en la especificación siguiente: los domingos, el día de año nuevo, el jueves y viernes de la Semana Mayor, el jueves de Corpus, el 16 de Septiembre, el $1^{\circ}$. y 2 de Noviembre y los días 12 y 24 de Diciembre.

2. En solo estos días dejarán de despachar habitualmente los tribunales, oficinas y comercio, exceptuándose las cosas urgentes, que sin necesidad de precio auto de habilitación de horas, pero sí expresando la razón por qué se declaró urgente el negocio, podrán despacharse.

3. Se derogan todas las leyes, circulares, disposiciones, cualesquiera que sean, emanadas del legislador, de institución testamentaria o de simple costumbre, por las cuales había de concurrir en cuerpo oficial a las funciones públicas de las iglesias.

Por tanto, mando se imprima, publique, circule y se dé el debido cumplimiento. Dado en el palacio del gobierno general en la $\mathrm{H}$. Veracruz, a 11 de agosto de 1859. -Benito Juárez-. Al C. Melchor Ocampo, secretario de Estado y del despacho de Gobernación"11.

Las reformas liberales secularizantes continuaron en 1860 con la Ley de Libertad de Cultos y la prohibición de celebrar ceremonias religiosas fuera de los templos; limita el uso de las campanas y prohíbe a funcionarios públicos y miembros del ejército a participar como tales en actos religiosos;

11 Segura, p. 131. 
en 1861 con el decreto de expulsión del delegado apostólico y los obispos más notables y la extinción de claustros y conventos, nacionalización de bienes de colegios y venta de conventos, se decreta sobre la libertad de imprenta y se suprime la censura a los teatros, la secularización de hospitales e instituciones de beneficencia, se suprime el ramo de negocios eclesiásticos en la estructura del gobierno federal, se declara al Catecismo Político Constitucional (de Nicolás Pizarro) "libro de asignatura" de todos los establecimientos de instrucción.

El 22 de diciembre de 1860, con el triunfo de las fuerzas liberales en la batalla de Calpulalpan, se dio por terminada la etapa armada de la Guerra de Reforma. Después de tres años de afanes, de que en más de un momento vieran su causa perdida, el gobierno liberal entró al Distrito Federal el 11 de febrero de 1861. Apenas una semana más tarde inició una ofensiva para arreglar la instrucción pública. Primero, definió el estatuto jurídico-administrativo del ramo de la instrucción. Un decreto del 18 de febrero mandaba que: "Artículo único. El despacho de todos los negocios de la instrucción pública, primaria, secundaria y profesional, se hará en lo sucesivo por el Ministerio de Justicia e Instrucción Pública"12.

Los problemas jurisdiccionales del decreto fueron advertidos por muchos. No señalaba claramente el ámbito de ejercicio del ministerio, aunque se asumía que era solo para el DF y los territorios. Desde la Constitución de 1824, que estableció una república federal, la instrucción pública era un asunto de los gobiernos estatales (excepto durante las repúblicas centralistas). La Constitución de 1857 en su artículo $3^{\circ}$ estipuló que "La enseñanza es libre. La ley determinará qué profesiones necesitan título para su ejercicio, y con qué requisitos se deben expedir". Ni el congreso ni el ejecutivo federal estaban facultados para ocuparse del ramo de la instrucción en el país, excepto en el Distrito Federal y territorios, pues según el artículo 117: "Las facultades que no están expresamente concedidas por esta Constitu-

12 "Decreto del gobierno que declara que pertenece a la Secretaría de Justicia el ramo de instrucción pública”, febrero 18 de 1861, Manuel Dublán y José María Lozano, Legislación Mexicana, T. IX, 85. 
ción a los funcionarios federales, se entienden reservadas a los Estados"13.

\section{La omisión de contenidos religiosos en el Distrito Federal}

La segunda disposición fue la Ley del 15 de abril de 1861, por medio de la cual se "Arregla la Instrucción Pública en el Distrito Federal y los Territorios", suscrita por el presidente Benito Juárez y el ministro de Justicia e Instrucción Pública, Ignacio Ramírez. Son varias las características y novedades de esta ley. No es este, desde luego, el lugar para abordarlas todas, solo las que atañen a la laicidad:

"De la instrucción primaria

Art. 1. La instrucción primaria, en el Distrito y Territorios, queda bajo la inspección del gobierno federal, el que abrirá escuelas para niños de ambos sexos, y auxiliará con sus fondos las que se sostengan por sociedades de beneficencia y por las municipalidades, á efecto de que se sujeten todas al presente plan de estudios.

2. El mismo gobierno federal sostendrá en los Estados profesores para niños y niñas, que se destinarán á la enseñanza, elemental en los pueblos cortos que carezcan de escuelas: estos profesores durarán solo dos años en cada lugar, y además del sueldo se les señalará una cantidad para gastos de viaje y compra de útiles.

3. Se establecerá inmediatamente en la capital de la República una escuela de sordomudos, que se sujetará al reglamento especial que se forme para ella; y tan luego como las circunstancias lo permitan, se establecerán escuelas de la misma clase, sostenidas por los fondos generales, en los demás puntos del país en que se creyere conveniente.

4. La instrucción primaria elemental comprende lo siguiente: moral, lectura, lectura de las leyes fundamentales, escritura, elementos de gramática castellana, Aritmética, Sistema legal de pesos y medidas, canto. Además, costura y bordado en las escuelas de niñas.

13 Constitución Federal de los Estados Unidos Mexicanos, sancionada y jurada por el Congreso Nacional Constituyente el día 5 de febrero de 1857. Esta constitución aparece indebidamente titulada como "Constitución Política de la República Mexicana de 1857, en Las Constituciones de México: 1824-1911 (México, Senado de la República, 1991), 215. 
5. La instrucción primaria elemental y perfecta, que se dará en un establecimiento modelo, y que servirá para proporcionar profesores á las escuelas de primeras letras, comprende los ramos siguientes: Lectura, Lectura de la Constitución, Escritura, Gramática castellana, Aritmética hasta los logaritmos, Álgebra, hasta las ecuaciones de segundo grado, Geometría elemental, Geografía, Economía política con aplicación á los negocios del país, Derecho internacional, Gramática general, Higiene en sus relaciones con la moral, Elementos de cronología y de historia general y del país, Dibujo lineal y de ornato, Teneduría de libros en partida doble, Idiomas inglés y francés por métodos prácticos, Ejercicios de natación y de armas, Sistema legal de pesas y medidas, Canto, Un oficio" $" 14$.

En primer lugar, hay que ver los aspectos jurisdiccionales. La instrucción primaria en el Distrito y territorios federales quedaron bajo la inspección del gobierno federal, pero no solo la vigilancia, sino la apertura de escuelas, el auxilio financiero a las de beneficencia y a las municipalidades. En los hechos implicó una mayor amplitud de la cobertura federal, porque el requisito para el apoyo a las escuelas era que se sujetasen al plan de estudios. La importancia de este aspecto reside en que la ampliación del arco estatal tuvo un mayor alcance en las decisiones de política, siguiendo el principio de la enseñanza libre. En segundo lugar, se observa la pretensión del gobierno federal de irrumpir en el ámbito de los poderes de las entidades federativas al incorporar a los maestros itinerantes y al tener la intención de abrir escuelas para sordomudos en "los demás puntos del país”, con fondos federales. En tercer lugar, y más significativo para nuestro tema, se modifican los contenidos educativos. El artículo $4^{\circ}$ especifica las materias que comprenden la primaria elemental. Se mantienen tres de las cuatro materias básicas: escritura, lectura y aritmética; omitiéndose el catecismo religioso. Se continúa con la gramática castellana, urbanidad y el sistema de pesos y medidas. Se adiciona además como contenido el canto.

14 "Decreto del gobierno para el arreglo de la instrucción pública en el DF y territorios federales", abril 15 de 1861, en Manuel Dublán y José María Lozan, Legislación mexicana, T. IX, 150-51. Esta misma ley aparece como "Ley sobre la instrucción pública en los establecimientos que dependan del gobierno general”, en Segura (ed.) (1861), pp. 243-251. 
Pero lo sorprendente es la desaparición del hasta entonces omnipresente catecismo religioso de la escuela primaria, de niños y de niñas, y también en la escuela modelo, de primaria elemental y perfecta para la formación de profesores de primeras letras. Se sustituye la enseñanza religiosa por una clase de moral para las primarias elementales, y otra de moral con aplicaciones a la higiene en la de profesores.

En esa misma Ley de 1861 se reglamentaron también los estudios preparatorios y superiores.

"De la instrucción secundaria

Artículo $6^{\circ}$ Se establece en el Distrito Federal: una escuela de estudios preparatorios y las escuelas especiales siguientes: de jurisprudencia, de medicina, de minas, que comprenderá las profesiones de minero, beneficiador de metales, ensayador, apartador y topógrafo; de artes, que comprenderá también el conservatorio de declamación, música y baile; de agricultura, de bellas artes, que comprenderá las carreras de pintor, escultor, grabador y arquitecto; de comercio.

Artículo $7^{\circ}$ En la escuela de estudios preparatorios se enseñará lo siguiente: latín, griego, francés, inglés, alemán, italiano, elementos de aritmética, álgebra, geometría, física, ideología en todos sus ramos, lógica, metafísica, moral, elementos de cosmografía, geografía, cronología, economía política y estadística, dibujo natural y lineal, elementos de historia general y del país, manejo de armas"15.

En el plan de estudios decretado por esta ley no hay contenidos que tengan que ver con religión, a diferencia del plan de estudios de 1854 que incluía como materias obligadas "Elementos de Historia sagrada" y "Religión y filosofía moral". Se hablaba indistintamente de la "instrucción secundaria" o de los "estudios preparatorios", que comprendían seis años en la Ley de 1854 y cinco años en la Ley de 1861. Los artículos del $8^{\circ}$ al $15^{\circ}$ se dedican

15 "Decreto del gobierno para el arreglo de la instrucción pública en el DF y territorios federales", abril 15 de 1861, en Manuel Dublán y José María Lozan, Legislación mexicana, T. IX, 150-51. Esta misma ley aparece como "Ley sobre la instrucción pública en los establecimientos que dependan del gobierno general”, en Segura (ed.) (1861), pp. 243-251. 
a describir los contenidos de cada una de las escuelas especiales y profesionales. En ningún artículo se incluyen contenidos que tengan que ver con religión de ninguna manera. Los catedráticos tenían que ingresar por riguroso concurso de oposición. La ley también se ocupó de la instrucción secundaria para niñas en los siguientes términos:

"Artículo 29. La enseñanza secundaria de niñas se hará por cuenta del gobierno en los colegios llamados de niñas y de las vizcaínas, las cuales se llamarán en lo sucesivo: el primero colegio de la caridad, y el segundo, colegio de la paz. Las bases de esta enseñanza serán las siguientes: lectura, escritura, lectura de la Constitución, aritmética, sistema legal de pesos y medidas, teneduría de libros, geografía, higiene con sus relaciones con la economía doméstica y con la moral, dibujo de animales, de flores y de paisajes, idioma español, francés, inglés italiano, costura y bordado, canto, música y baile, declamación, ejercicios gimnásticos, jardinería, dorado de cuadros, construcción de flores artificiales, composición de imprenta”.

No es nuestra intención evaluar aquí la viabilidad o no del complejo $c u$ rriculum que se estaba decretando, ni las implicaciones sociales que tenía. Sin embargo, queremos hacer notar la pretensión de Ignacio Ramírez de brindar a las mujeres una educación similar a la de los hombres, y en este caso, con contenidos incluso más ambiciosos. Es preciso señalar que la "instrucción secundaria” se entendía como una "enseñanza superior", en la cual las mujeres habían sido excluidas, y a pesar de esta innovadora legislación, continuarían así por algunas décadas más ${ }^{16}$.

Así se tratara del curriculum de la instrucción primaria, la instrucción secundaria para niños o niñas, o la educación superior, lo nuevo era la omisión total de contenidos religiosos. Había una oportunidad política: se había ganado la Guerra de Reforma, por lo que se trataba de continuar impulsando la independencia Estado-Iglesia, en todos los ámbitos de la admi-

16 María de Lourdes Alvarado, La educación “superior” femenina en el México del siglo XIX. Demanda social y reto gubernamental (México: Universidad Nacional Autónoma de México, Centro de Estudios sobre la Universidad / Plaza Valdés, 2004). 
nistración pública. La instrucción era uno de ellos, como el financiero, de justicia, civil y hospitalario. En este caso, no se trataba de secularizar la regulación de la instrucción pública, que tenía décadas sometida a leyes específicas y organismos de gestión estatal, sino de distanciar la formación de los ciudadanos de las creencias religiosas, por motivos tanto políticos como pedagógicos. El mismo Ramírez lo explicaba años más tarde, en sus debates periodísticos:

“Se trata de formar una sociedad enteramente jerárquica, donde todos obedezcan y muy pocos piensen, donde el arte sea rutina y donde la ciencia enmudezca cuando se habla el dogma? ¿Se trata de retroceder hasta los siglos de la barbarie? ¿Se quiere que el sacerdote nos acompañe en la cuna, en el lecho conyugal, en la tribuna, en el foro, en los placeres, en las desgracias y hasta en las puertas de la muerte? ¿Se proclama como perfección administrativa el sistema teocrático? Entonces, el cura de la Sierra es lógico cuando propone a la humanidad como el primero, y para la mayoría como el único libro, el catecismo del padre Ripalda. ¡Creed, temblad, trabajad para nosotros!

Pero los pueblos más poderosos de la tierra, hoy se agitan con otras aspiraciones; el trabajador busca su independencia en el provecho, protegido por la costumbre y por las leyes; ninguno tiembla fácilmente cuando vive entre iguales, y las ciencias y las artes no crecen sino entre los rayos de la demostración y de la experiencia. La soberanía individual rechaza los dogmas, porque todo dogma es una voluntad ajena y toda soberanía quiere ser independiente. En medio de una discusión universal, cuando los instrumentos más ingeniosos se multiplican para descubrir la verdad, cuando la naturaleza complacida nos prodiga sus antiguos secretos, ¿qué asiento pueden tener entre nosotros las revelaciones ni los oráculos? Lo absurdo podrá creerse, pero jamás figurará ni entre las artes ni entre las ciencias"17.

17 Ignacio Ramírez, “Carta al Sr. Lic. D. Ignacio Altamirano”, El Federalista, t. I, No. 67, lunes 19 de marzo de 1871, 1. 
Los diarios católicos registraron el acontecimiento, pero inmersos como estaban en explorar los saldos de la guerra, enfocaron sus baterías a los problemas de los diezmos, los conflictos de la nacionalización de los bienes eclesiásticos y las instrucciones de obispos y clérigos. En un recuento de las acciones desarrolladas por el gobierno desde su entrada a la ciudad de México, el periódico La Unidad Católica, en su primer número, registró lo siguiente:

\begin{abstract}
"Mayo 4. Publícase la ley sobre instrucción pública, expedida por conducto del ministerio de justicia el 15 de abril. En dicha ley se hace de la instrucción religiosa punto omiso, y se declara que pertenecen a los fondos del ramo los capitales, cesan renta, que tiene actualmente entre otros establecimientos, los colegios de Niños, de Vizcaínas y de Belem, entre los que se comprenden los bienes pertenecientes a obras pías del colegio de Belén, y a las moras de Aránzazu y su cofradía del Santísimo; también pasan al fondo de instrucción pública los bienes del Seminario Conciliar y del Colegio de Tepozotlán"18.
\end{abstract}

\title{
3. LA OMISIÓN DE CONTENIDOS RELIGIOSOS EN LAS ENTIDADES FEDERATIVAS
}

Quizá no haya sido la primera vez que la religión desapareciera de los ramos de la instrucción. De hecho, ya estaba ausente en planes de estudios secundarios y superiores. Algunos historiadores estatales de la educación han ubicado disposiciones jurídicas que anteceden a la Ley Ramírez; por ejemplo la Ley de Instrucción Pública de Oaxaca, expedida el 8 de diciembre de 1860, con la misma formulación, como lo dice Fidel López en su estudio sobre la historia de la educación en Oaxaca:

"El programa de las escuelas elementales primarias, nombre que se da a las escuelas de primeras letras, se debería desarrollar en dos años. En el primer año se enseñaría a leer y escribir correcta-

18 "Disposiciones promulgadas en México desde el 25 de diciembre de 1860 hasta el 15 de mayo de 1861 relativas a la iglesia", La Unidad Católica, periódico religioso y literario, de noticias nacionales y extranjeras, de ciencias, variedades y anuncios, México, miércoles 15 de mayo de 1861, 2. 
mente, Gramática castellana e instrucción moral, y en el segundo, leer y escribir, aritmética elemental, con el cálculo legal de pesas y medidas e instrucción civil" 19 .

En otros estados la omisión en el curriculum precedió escasamente a la Ley Ramírez. En el Estado de México, en la Constitución Política del Estado, con fecha el 12 de octubre de 1861:
"se suprimen las prácticas religiosas en los planteles oficiales, pues al indicar los ramos de enseñanza que deberán impartirse (leer, es- cribir, las cuatro primeras reglas de aritmética y catecismo político), excluye el catecismo religioso, que invariablemente se había inclui- do con carácter obligatorio, en todas las leyes y decretos expedidos para reglamentar este tipo de trabajos desde 1824"20.

Era esta una legislación casi calcada de la Ley Ramírez, pero en el texto constitucional de una entidad federativa, inusual en la época. En la legislación del Estado de México, a medio camino entre una escuela sin religión obligatoria, pero que podía otorgarla si los padres de familia así lo solicitaran, se guardaba la misma perspectiva que las circulares y prevenciones del gobierno de la república para el Distrito y los Territorios Federales, aunque con menor determinación, pues el gobernador Berriozábal decretó:
"una serie de disposiciones, a cual más importantes, como la de ordenar la instalación de escuelas para adultos anexas a las de niños y la enseñanza de la religión cristiana en todas ellas, cui- dando no chocar con los mandatos constitucionales que estable- cían neutralidad en ese aspecto, previniendo que "luego que se establezca en el Estado algún culto diverso, cuidará el Gobierno de proveer esta necesidad eficazmente. La clase de doctrina no será obligatoria más que para los niños cuyos padres o tutores lo quisieran" $"$.

19 Fidel López Carrasco, Historia de la educación en el estado de Oaxaca (México: Publicaciones del Museo Pedagógico Nacional, 1950), 33.

20 Gobierno del Estado de México, 150 años de educación en el Estado de México (México: Editorial Libros de México, 1974), 46.

21 Gobierno del Estado de México, 150 años de educación... 47. 
Un caso remarcable es la Ley de Instrucción Pública del estado de Tamaulipas, expedida el 19 de agosto de 1861, en la que "reconoce el Estado la obligación de sostener, dirigir y vigilar la enseñanza escolar, que debe ser obligatoria, gratuita y laica" 22 . Remarcable porque en esta ley se utiliza expresamente el concepto de enseñanza laica. En el capítulo relativo a la Junta de Instrucción Pública se establecían sus funciones, entre las que estaban:
"procurar que los alumnos recibieran la mayor instrucción en las materias de lectura, escritura, aritmética y gramática castellana, debiendo también vigilar para que se inculcara en la juventud el amor, la veneración y los deberes que debe tener para con su patria" 23 .

Desde luego, no en todos los estados sucedió lo mismo. En San Luis Potosí, por las mismas fechas, la sola mención periodística de la conveniencia de desterrar la religión de las escuelas públicas desató una andanada de críticas, repudios y visitas al gobernador, que cerró la posibilidad por el momento. Así lo registra uno de los historiadores decimonónicos de la educación en el Estado:

"Siendo redactor del periódico oficial del estado el Lic. D. Francisco Macías Valadez, causó alguna sensación en el público un editorial firmado por dicho Señor, en el que sostenía la conveniencia de que en las escuelas públicas se aboliera la enseñanza de la doctrina cristiana por el Padre Ripalda, sustituyéndola con lecciones generales de moral.

Se creyó que eran ideas autorizadas por el Gobierno que irían brevemente a ponerse en práctica, y con tal motivo se acercaron al Gobernador, comisiones y personas particulares a pedirle que no se expidiera esa disposición. El Gobernador contestó que no había orden del gobierno en ese sentido ni se había discutido el punto en los acuerdos. 
No se volvió a hablar más de ese asunto, pero el Sr. Macías Valadez logró después de algunos años ver realizadas sus ideas en ese particular porque así lo exigía el cumplimiento de las leyes fundamentales del país"24.

En conjunto, estos ejemplos ubican la emergencia del primer elemento del régimen de laicidad, la omisión de la enseñanza religiosa en la instrucción primaria, en el triunfo liberal de la guerra de reforma, como derivadas de las leyes de reforma promulgadas en circunstancias peculiares en 1859-61. De hecho, hay quienes consideran a la Ley Ramírez como parte sustantiva de las leyes de reforma -pero en estricto sentido deberían considerarse como tales a las de todos los estados, no solo la del DF; lo que es indudable en términos estratégicos. Se trata del desarrollo y aplicación de los principios de la Reforma a la instrucción, un caso particular, del mismo modo como se estaba realizando en otros ramos de gobierno, tales como cementerios y hospitales, de continuar la separación Estado-iglesia, la secularización de los procesos biopolíticos, y los derechos naturales del hombre y del ciudadano.

\section{El Dispositivo JURÍDICO-ADMINISTRATIVO}

La Ley Ramírez, y todas las estatales que la antecedieron y la sucedieron en materia de laicidad, son resultado del triunfo político y militar de los liberales, sin duda; pero también conceptual, es decir, de nociones de gobierno, de régimen político y modelo de regulación de la instrucción pública. Esto es lo que explícitamente se manifiesta en las circulares y providencias del ramo. Una de ellas es la circular del 26 de marzo de 1863 (emitida cuando Francia había iniciado ya la invasión del país), en la que se esclarece la libertad religiosa en los colegios:

"Pugnando con las prescripciones de la ley general sobre libertad religiosa, la disposición de los reglamentos de los establecimientos de enseñanza que previene se exija a los alumnos la obser-

24 Manuel Muro, Historia de la instrucción pública en San Luis Potosí (San Luis Potosí: Impr. Lit. Enc. y Libr. de M. Esquivel y Cía., 1899), 135-136. 
vancia forzosa de ciertas prácticas religiosas, como la confesión y comunión que manda la iglesia Católica, especialmente en el tiempo llamado de Cuaresma, el C. Presidente ha tenido a bien disponer, que mientras se dictan las disposiciones generales que deben regir en los colegios sobre enseñanza y prácticas religiosas, se prevenga a los rectores y directores de los establecimientos de instrucción pública, que por ningún motivo se exija forzosamente a los alumnos esas prácticas, dejándoles en este punto en plena libertad para seguir las inspiraciones de su conciencia; sin que por ningún motivo se permitan los superiores hacerles indicaciones en ese sentido, ni mucho menos ejercer coacción alguna.

Como el poder que los rectores y profesores ejercen sobre sus educandos es una delegación de la patria potestad y no de la autoridad pública, mientras los hijos estuvieren en poder del padre y este pida se le entreguen para hacerles observar las prácticas religiosas que juzguen convenientes, los dichos rectores los entregarán sin oponer obstáculo alguno al ejercicio de la autoridad paterna" 25 .

Así, a la sustitución de la religión por la moral por sí mismo una declaración enfática de la laicidad: ¡Una moral sin religión! ¡La formación de ciudadanos de una nación fundada en la soberanía del pueblo, y no la formación de fieles de una nación independiente la acompaña un criterio de interpretación presidencial: mientras se dictan las disposiciones sobre religión en escuelas, en las primarias públicas no debe exigirse por ningún motivo someter a prácticas religiosas a los alumnos; y respetando el derecho de los padres a definir la educación de sus hijos, solo ellos podrían entregarlos a los ritos y costumbres religiosas de su preferencia.

La desaparición de la religión, en consecuencia, es una parte de los dispositivos de las leyes de reforma y de la separación Estado-Iglesia; pero, además, complementada con la libertad de enseñanza y el derecho de los padres sobre la educación de sus hijos. Un liberalismo extremo, se diría

25 "Circular de la Secretaría de Justicia. Sobre la libertad religiosa en los colegios", marzo 26 de 1863, Manuel Dublán y José María Lozan, Legislación mexicana, T. IX, 603. 
ahora, con tres elementos: la libertad de enseñanza; derechos de los padres sobre la educación de sus hijos, e independencia Estado-Iglesia.

En otra providencia, el secretario de la gobernación informa al presidente de la Compañía Lancasteriana la prohibición de contenidos y prácticas religiosas en las escuelas subvencionadas con fondos públicos:

"Una vez promulgada la ley del 4 de diciembre 1860, no puede el gobierno ni sus agentes intervenir en ningún modo en las creencias y prácticas religiosas. La autoridad tiene que proteger la libertad de conciencia, en tanto que su ejercicio no afecte el derecho público y o privado de la nación; mas precisamente para conservar esta garantía, necesita abstenerse de sostener y propagar las doctrinas y preceptos de un culto cualquiera.

Por estas causas, el presidente se ha servido ordenar que en todos los establecimientos dirigidos por esa compañía, como costeados por los fondos públicos, cese la instrucción y la práctica religiosas, debiendo quedar estos puntos bajo el cargo de los padres, tutores o instructores privados" ${ }^{\prime 26}$.

Se encuentra en este razonamiento administrativo la pinza jurídica y política de la eliminación de la enseñanza religiosa en las escuelas públicas, lo que ahora se denominaría el contenido esencial de la educación laica. En primera instancia, la separación Estado-Iglesia; en segunda, la neutralidad del Estado respecto a las religiones, en el sentido dual de no intervenir - por lo mismo no mostrar preferencia por ninguna de ellas-, pero tampoco perseguir o denostar; en tercera, la libertad de enseñanza y de creencia, por lo que el criterio laico es exclusivo de las primarias sostenidas o subvencionada con fondos públicos; en cuarto, la remisión de la religión al ámbito privado, familiar y educativo. No es, como dice Meneses, un primer momento implícito de la educación laica ${ }^{27}$, es el momento de su fundación legislativa, de su definición: se excluye la religión de los ramos de la instrucción primaria pública, más aún, cesa la enseñanza de la religión

26 "Providencia de la Secretaría de Gobernación. Ordena que cesen la instrucción y prácticas religiosas en los establecimientos costeados por fondos públicos”, marzo 30 de 1863, Manuel Dublán y José María Lozano, Legislación mexicana T. IX, 603.

27 Ernesto Meneses Morales, Tendencias educativas oficiales, 1911-1937 (México: CEE, 1986), 737. 
en las lancasterianas y de financiamiento estatal; y se impide la coacción a los alumnos para participar en ritos religiosos. No son implícitos, son los principios de activación misma de la laicidad educativa.

\section{Conclusiones}

Todos los elementos de un régimen de laicidad se encuentran en unas pocas disposiciones jurídicas. Conceptualmente ya está definido. No es una sencilla omisión del catecismo religioso; tampoco una mera sustitución del ramo religioso por el de moral universal, sino que son planes de instrucción pública que se articulan en un rediseño institucional del Estado, lo que, para ser coherentes, tendría que observarse en posteriores legislaciones, en las que se trataran de manera más específica los objetivos formativos, los contenidos, técnicas y prácticas didácticas, la formación de profesores, los estudios secundarios y superiores. Y eso fue lo que ocurrió, con la salvedad de la Intervención Francesa y el denominado Segundo Imperio (1863-1867).

A unos meses de haberse restablecido la república en julio 1867, se confirma la omisión de la religión y la sustitución por la moral universal en el curriculum escolar en una nueva Ley Orgánica para el Distrito Federal en la que se plantea esencialmente lo mismo que en 1861, además de mantener la regulación estatal de la instrucción, la gratuidad y de introducir la obligatoriedad de la instrucción primaria, que ya había estado presente en las disposiciones de las leyes estatales con algunas décadas de antelación. Fue algo más que una tendencia, más que una mera formalización legislativa, pues se acompaña de circulares, declaraciones y providencias en donde se aclara el ámbito de ley -circunscrita a la primaria pública, y las escuelas subvencionadas o apoyadas con fondos públicos, municipales o nacionales-; se reconoce el derecho de los padres de proporcionar enseñanza religiosa, y se circunscribe esta, por las leyes de culto público y tolerancia religiosa, al ámbito familiar y privado.

\section{Bibliografía}

\section{Fuentes primarias}

Acta Constitutiva de la Federación Mexicana. México: Imprenta del Supre- 
mo Gobierno en Palacio, 1824.

Baraja, Pantaleón. Historia Parlamentaria del Cuarto Congreso Constitucional. México: Imprenta de I. Cumplido, 1872-74. 4 tomos.

"Circular de la Secretaría de Justicia. Sobre la libertad religiosa en los colegios", marzo 26 de 1863, en Manuel Dublán y José María Lozano, Legislación mexicana, T. IX, 603. México: Imprenta del Comercio de Dublán y Chávez a cargo de M. Lara, hijo, 1877.

Congreso del Estado de Nuevo León. Reseña histórica de la instrucción pública en Nuevo León desde sus orígenes hasta 1891, presentada por el Congreso del ramo al Superior Gobierno del Estado. Monterrey, N. L: Tip. del Gobierno, 1894.

Constitución Federal de los Estados Unidos Mexicanos, sancionada y jurada por el Congreso Nacional Constituyente el día 5 de febrero de 1857. México, Imprenta de I. Cumplido, 1857.

“Constitución Política de la República Mexicana, de 1857”. En Las constituciones de México: 1824-1911. México: Senado de la República, 1991.

"Constitución Política de los Estados Unidos Mexicanos". Diario Oficial de la Federación (DOF), lunes 5 de febrero de 1917.

"Disposiciones promulgadas en México desde el 25 de diciembre de 1860 hasta el 15 de mayo de 1861 relativas a la iglesia”. La Unidad Católica, periódico religioso y literario, de noticias nacionales y extranjeras, de ciencias, variedades y anuncios, México, 15 de mayo de 1861.

Dublán, Manuel, y José María Lozano. Legislación mexicana o colección completa de las disposiciones legislativas expedidas desde la Independencia de la República. Tomos I al XIX. México: Imprenta del Comercio de Dublán y Chávez a cargo de M. Lara, hijo, 1877.

"Ley sobre la instrucción pública en los establecimientos que dependan del gobierno general". En Código de la Reforma o Colección de Leyes, Decretos y Supremas Órdenes, expedidas desde 1856 hasta 1861, Tomo I . editado por Sebastián J. Segura. México: Imprenta Literaria, 1861, 243-251.

Segura, J. Sebastián. Código de la Reforma o Colección de Leyes, Decretos y Supremas Órdenes, expedidas desde 1856 hasta 1861, Tomo I. México: Imprenta Literaria, 1861.

Senado de la República. Las Constituciones de México: 1824-1911. México: Senado de la República, 1991. 
"Providencia de la Secretaría de Gobernación. Ordena que cesen la instrucción y prácticas religiosas en los establecimientos costeados por fondos públicos”, marzo 30 de 1863, Manuel Dublán y José María Lozano, Legislación mexicana T. IX, 603.

Ramírez, Ignacio. "Carta al Sr. Lic. D. Ignacio Altamirano”. En El Federalista, t. I, No. 67, 19 de marzo de 1871.

\section{Fuentes secundarias}

Alvarado, María de Lourdes. La educación “superior" femenina en el México del siglo XIX. Demanda social y reto gubernamental. México: Universidad Nacional Autónoma de México, Centro de Estudios sobre la Universidad/Plaza Valdés, 2004.

Arredondo, Adelina, y Roberto González Villarreal. "De la secularización a la laicidad educativa en México", Historia de la Educación. Anuario SAHE Vol. 15 No. 2 (2014): 140-167.

Arredondo, Adelina, y Roberto González Villarreal. "La educación laica en las reformas constitucionales, 1917-1993", Inventio, Vol. 8 No. 16 (sep. 2012-marzo 2013): 49-56.

Cantón Rosado, Francisco. Historia de la instrucción pública en Yucatán. Desde fines del siglo XVI hasta fines del siglo XIX. México: Ediciones de la SEP, 1943.

García García, Raúl. Apuntes para la historia de la educación en Tamaulipas. Ciudad Victoria: Universidad Autónoma de Tamaulipas, 1980.

García González, Francisco. Conciencia e inteligencia en Zacatecas. Sociedad, educación, historia (1350-1890). Zacatecas: El Arco y la Lira, Universidad Autónoma de Zacatecas, 1988.

Gobierno del Estado de México, 150 años de educación en el Estado de México. México: Editorial Libros de México, 1974.

Heredia, Roberto. “La educación en Michoacán 1831-1861. Datos y cifras (I)”, Relaciones No. 21 (invierno de 1985).

Herrejón Peredo, Carlos. "Fundación del Instituto Literario del Estado de México: Testimonios históricos". Toluca: Universidad Autónoma del Estado de México, 1978.

López Carrasco, Fidel. Historia de la educación en el estado de Oaxaca.

México: Publicaciones del Museo Pedagógico Nacional, 1950.

Martínez Vásquez, Víctor Raúl. Historia de la educación en Oaxaca. De la 
Independencia a la Revolución. Oaxaca: IIS-UABJO, 1993.

Meneses Morales, Ernesto. Tendencias educativas oficiales. 1911-1937. México: CEE, 1986.

Muro, Manuel. Historia de la instrucción pública en San Luis Potosí. San Luis Potosí: Impr. Lit. Enc. y Libr. de M. Esquivel y Cía., 1899.

North, Douglass. Instituciones, cambio institucional y desempeño económico. México: FCE, 1993.

Ruiz Cervantes, Francisco José. Un siglo de legislación educativa en Oaxaca. Oaxaca: Casa de la Cultura, 1987.

Tanck, Dorothy. La educación ilustrada, 1786-1836. México: El Colegio de México, 1984.

Para citar este artículo: González Villarreal, Roberto y Arredondo, Adelina. "1861: la emergencia de la educación laica en México", Historia Caribe Vol. XII No. 30 (Enero-Junio 2017): 25-49. DOI: http://dx.doi. org/10.15648/hc.30.2016.2 